\title{
Professor, quem inventou a Matemática? Travessias de uma pergunta que se torna problema e um problema que inventa currículo
}

\author{
Teacher, who invented mathematics? Crossings of the question that becomes a problem, \\ and of a problem that invents curriculum
}

\author{
Sônia Maria Clareto \\ sclareto@yahoo.com.br
}

\begin{abstract}
Resumo
Este artigo se abriga junto a uma pesquisa realizada em uma escola municipal de Juiz de Fora (MG). Em uma sala de aula de matemática um aluno pergunta: professor, quem inventou a matemática?. Esta pergunta dispara inquietações e desassossegos e é tornada problema junto a toda a escola. Alunos e alunas, professores e professoras das turmas de educação infantil, anos iniciais e anos finais do Ensino Fundamental são convocados pela questão disparadora e se lançam em invenções construindo possibilidades de enfrentamento da pergunta: quem inventou a matemática?. Neste enfrentamento um currículo vai sendo inventado. Currículo como movimento de produção de questões. Currículo sendo inventado por um problema. Um indisciplinar atravessa o Currículo. O artigo está organizado em quatro tópicos: no primeiro deles, se dispõe a pensar o quem? da pergunta lançada; no segundo, o verbo inventar em seu tempo verbal; no outro, a matemática é interrogada: que matemática?; por fim, é recolocada a questão inicial, que emerge inventada de outros modos no processo desta escrita: quem inventa matemática na escola?
\end{abstract}

Palavras-chave: Matemática; Sala de aula; Currículo; Problema.

\begin{abstract}
This paper comes along with a research carried out in an public elementary school in Juiz de Fora - MG. In a class of mathematics a student inquires: Teacher, who invented mathematics? This question triggers unsettledness and disquietedness and it becomes an inquiry along the entire school. Students, teachers from early years and final years of elementary school are asked by this trigging question and they put themselves under inventions by constructing possibilities to confront this inquiry: Who invented mathematics? In this confrontment a curriculum begins to be created. Curriculum as a movement of question production that takes multiple entries and a plurality of inventive processes. An undisciplined crosses the curriculum. The paper is organized in four topics: In the first one, concerns to think about the particle "who" of the question made; the second one, the verb to invent in its verbal tense; in the other one, mathematics is inquired: which mathematics?; Lastly, it is replaced the initial question that comes up modified in the process of the following sentence: who invented mathematics in school?
\end{abstract}

Keywords: Mathematics; Classroom; Curriculum; Problem.

O cotidiano é o incógnito do mistério. Mário Quintana

Entre banalidades de um cotidiano escolar ${ }^{1}$, uma pergunta, entre muitas lançadas, inventa problema - interroga, desassossega, inquieta - e rompe com uma quietude dada pela

\footnotetext{
${ }^{1}$ A cotidianidade escolar aqui referida é tomada junto a uma escola municipal da cidade de Juiz de Fora, na qual vem sendo desenvolvida, desde setembro de 2013, a pesquisa: POR UMA EDUCAČ̃̃ MATEMÁTICA MENOR: currículo e formação de professores junto à sala de aula de matemática (CAPES/FAPEMIG, Processo $n^{\circ}$ APQ 03480-12).
} 
sensação de que tudo permanece, de que cada coisa ocupa o seu lugar devido na escola. Problema que, rompendo silêncios, abre-se em interrogações: professor: quem inventou a matemática? Mais silêncio. Silêncios. Quem inventou a matemática?

De dentro de uma sala de aula brota uma questão que vaza, indisciplinarmente, para toda a escola.

Na sala de aula: um dentro...

Uma porta: um limite. Um dentro, um fora.

A porta impõe um limite? Delimita uma vida. Vida de e em sala de aula. Uma vida? Um dentro e um fora?

Na sala de aula: movimentos, silêncios, inquietações, dentros e foras... ${ }^{2}$

Dentros: dentro da proposta curricular, dentro da disciplinarização curricular, dentro das regras da didática, dentro do tempo estipulado para cada aula, dentro do aceitável, dentro do permitido, dentro do programado...

Foras: fora do pensado, fora do programado,

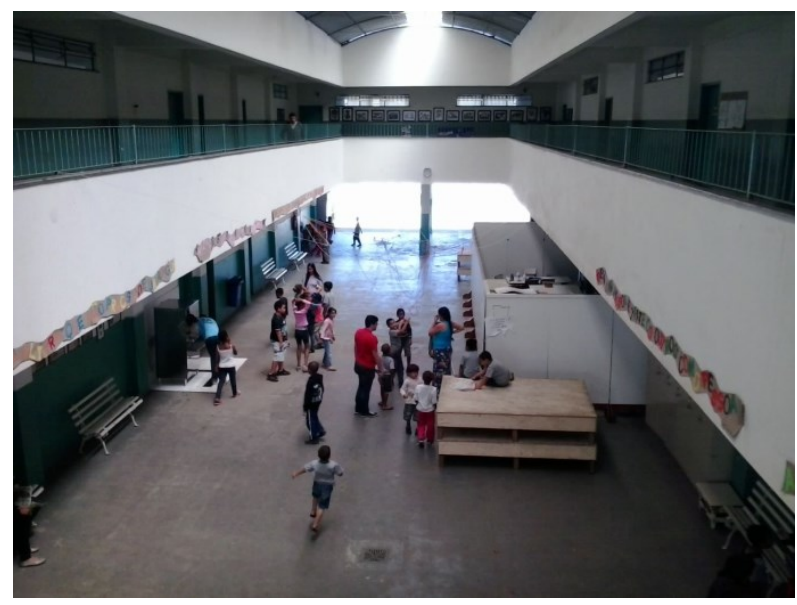
fora do previsto, fora da disciplinarização curricular, fora da ordem, fora do tempo, fora do explicável, fora do aceitável... ${ }^{3}$

Uma pergunta se põe e se impõe indisciplinarmente:

-Professor, quem inventou a matemática? Pergunta um aluno sentado no fundo da sala.

O professor procura por um a resposta... dá alguns passos em direção ao aluno e, se contorcendo, lança:

\footnotetext{
${ }^{2}$ Este artigo foi elaborado junto a uma política de narratividade que coloca esta escrita como uma composição com imagens. Portanto, não se trata de ilustração ou figuração, mas as imagens entram em composição sendo parte da própria escrita, configurando-se mais como elemento de escrita do que como elementos ilustrativos. Imagens como texto. Texto em imagens. Portanto, as imagens não serão identificadas por legendas, ficando, assim, em desacordo com as normas da ABNT, a bem da política e da estética nas quais esta escrita se abriga.

${ }^{3}$ As imagens que aparecem neste artigo foram produzidas ao longo da pesquisa na qual esta escrita se enreda e faz parte do acervo organizado e mantido pela equipe de pesquisadores
} 
-Você não precisa saber quem inventou a matemática! Você precisa saber quem inventou a educação.

-Ah, essa é fácil, professor, foi minha mãe...

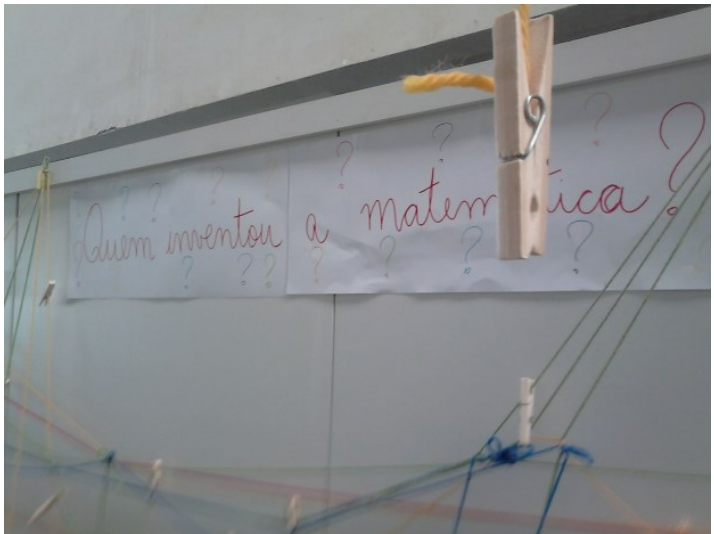

Uma pergunta vaza de dentro da sala: rompe seus limites e ocupa o pátio da escola. Escrita em tira de papel e colada na parede do pátio central, uma pergunta abre a sala de aula para seu fora. Um fora que é o próprio pátio escolar, o mais de dentro: Quem inventou a matemática?

Uma teia que enreda fios de lã: entre azuis, verdes e vermelhos pregadores de roupa se oferecem como instrumentos de fixação: uma rede que prende, captura, agrega... Mas também, lança(-se) em desafio: quem inventou a matemática?

Um problema agencia afetos e efeitos: mostra-se em encontros de crianças e adolescentes, alunos das diferentes séries, com idades distintas... capturados pela rede: máquina que prolifera respostas em pergunta: quem inventou a matemática?

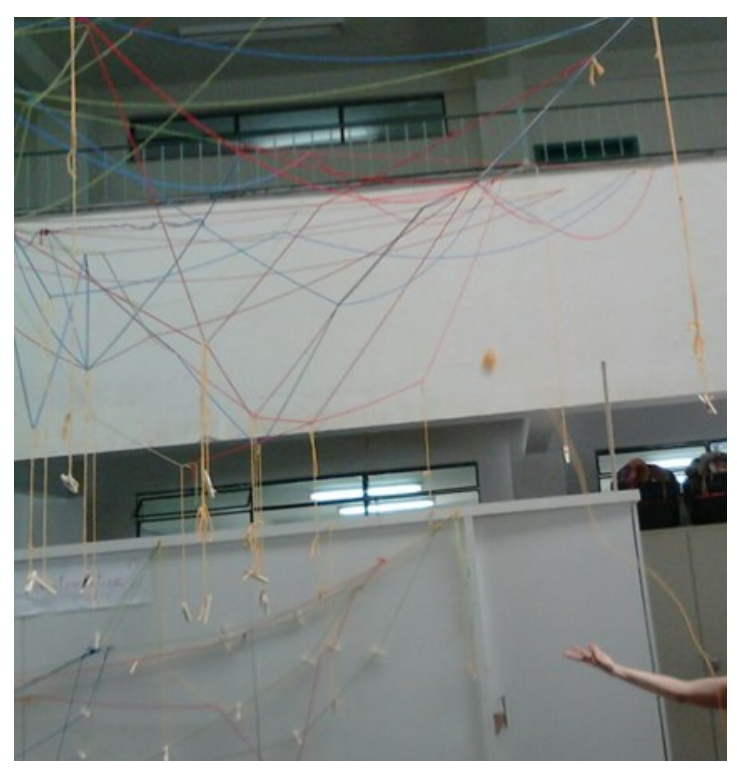

Enquanto a teia está sendo amarrada, bem no meio do pátio da escola, crianças correndo ensejam mais perguntas: - o que é isso? - Pra quê que serve?

Entre gritinhos de crianças e cheiros de escola e cores de escola e entusiasmos de crianças e cotidianidades de escola e gritos de professores e protestos de alunos e... uma teia se faz captura: atraia e enreda a atenção:

- o que é isso? - Pra quê que serve?

- Ah, eu sei, é uma rede para prender crianças... que medo!!!

\section{Quem inventou a Matemática?}


E a pergunta, em tira de papel, se faz parede e clama por enfrentamentos: Quem inventou a matemática?

- Ah, foi você, professora!

- Não seu bobo, foi o cientista...
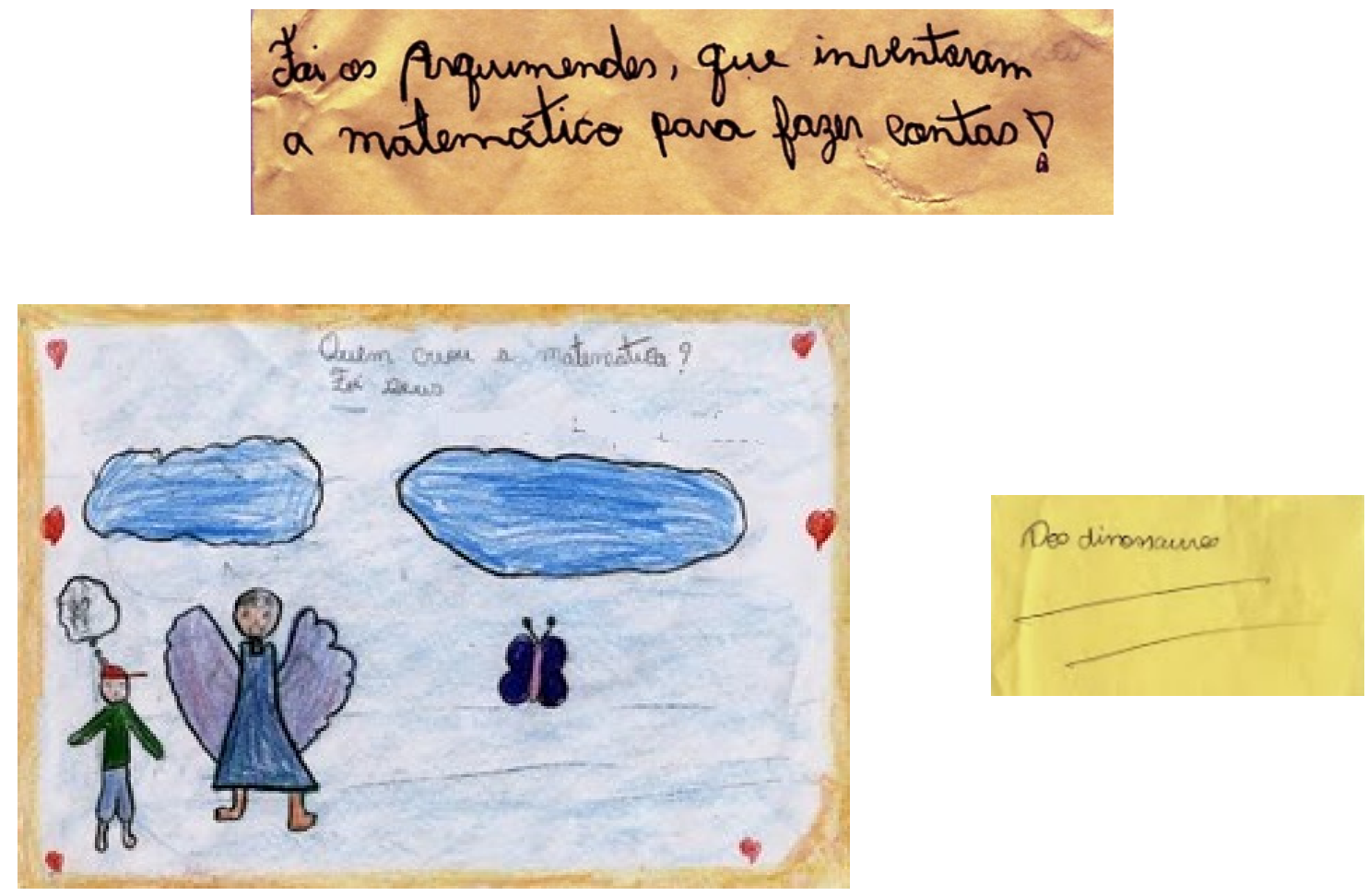

Em maquinações, vão sendo disparados modos de enfrentamento do problema que colocam em foco maneiras mais hegemônicas de compreender a produção de conhecimentos - no caso do conhecimento matemático - mas também torcem essas maneiras, tramando sentidos outros.
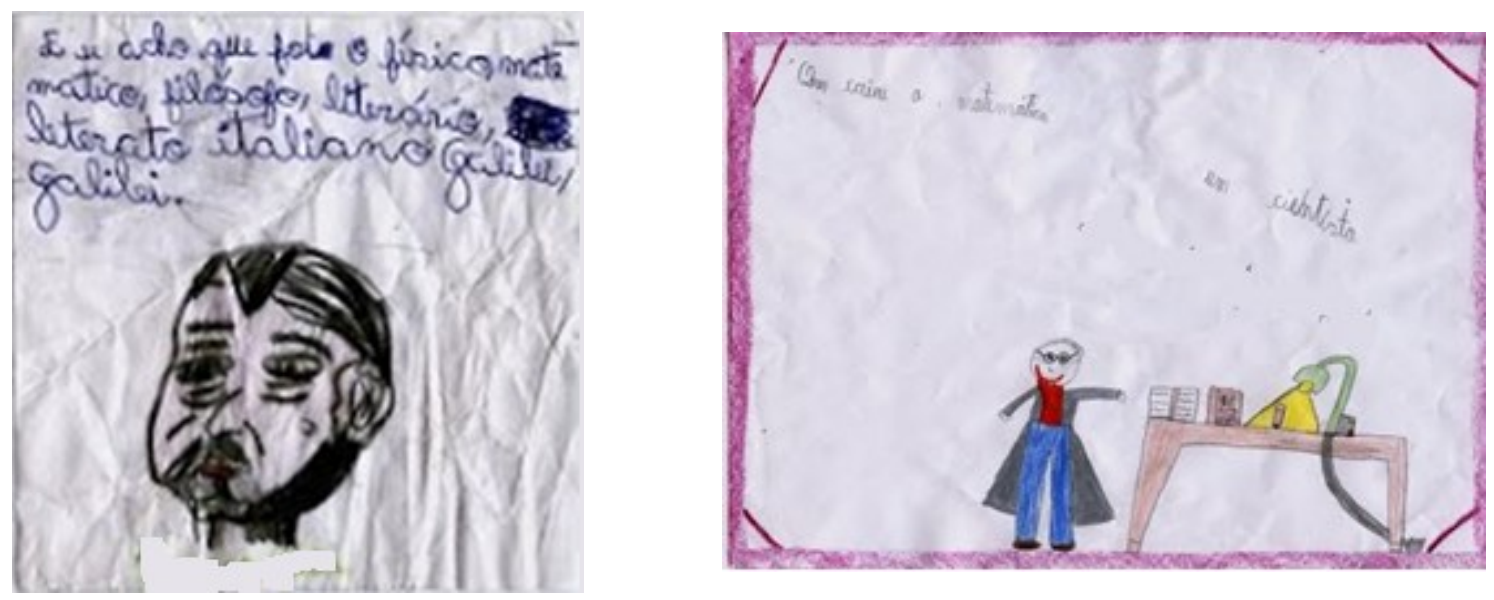
A questão quem? não reclama pessoas, mas forças e quereres. (DELEUZE, 1997, p. 114)

Que forças, que quereres, então, se apoderam de uma pergunta? Que forças, que queres se agenciam na produção de uma matemática? Que forças, que quereres clamam por respostas, por pesquisas e investigações junto a alunos de uma escola pública diante da questão: quem inventou a matemática?

Quem inventou a matemática não reclama por pessoas, mas por forças e quereres... que forças, que quereres inventaram uma matemática?
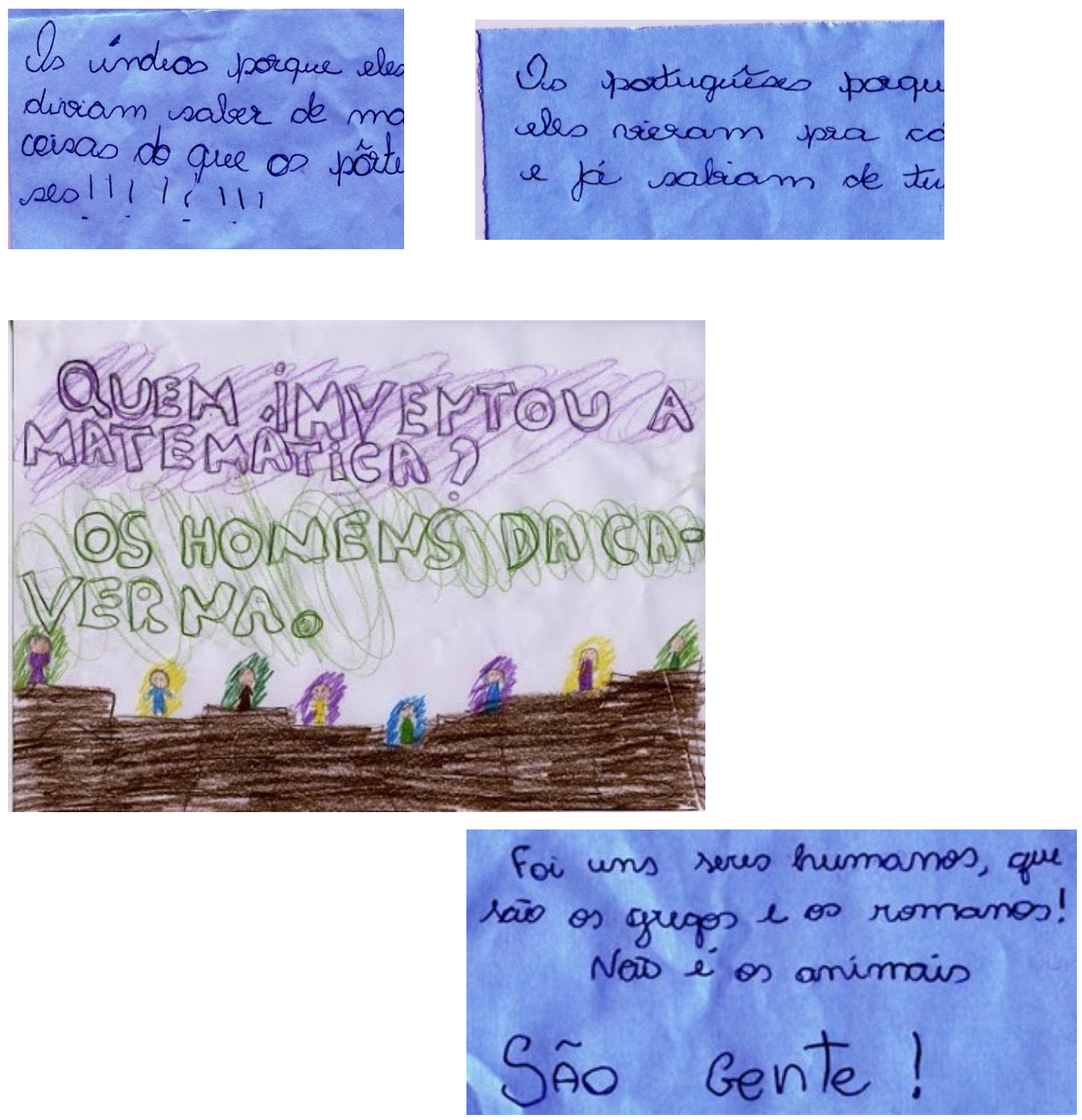

Que forças, que queremos instigam uma invenção de uma matemática? Invenção na qual o "quem inventa" são as forças e os quereres. Forças e quereres que inventam uma 
matemática lançada ao mundo. Lançada a uma escola que se pergunta: quem inventou a matemática?

\section{Quem inventou a Matemática?}

Ao colocar a pergunta - quem inventou a matemática? - há já uma certa compreensão se mostrando: a matemática foi inventada! Houve invenção de matemática! Quanto de inquietação guarda esta afirmação? Uma matemática inventada!

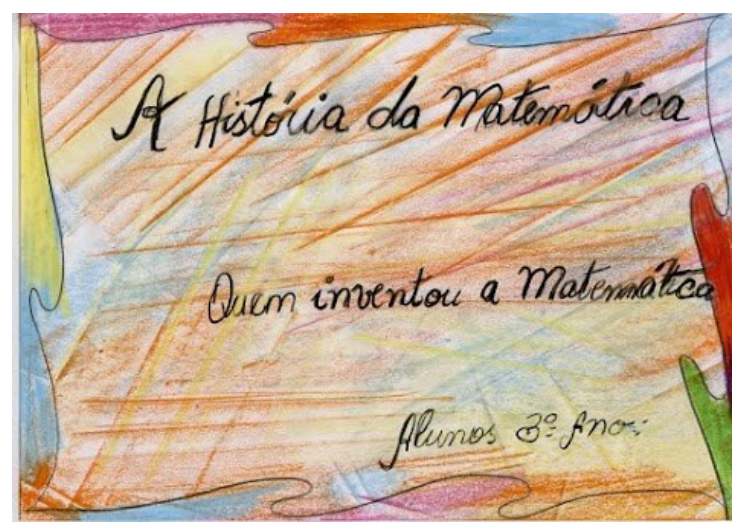

Inquietações em desdobra: não seria a matemática uma realização da própria natureza ou da materialidade do mundo ${ }^{4}$ ? A matemática já não é no mundo, desde que o mundo é mundo $^{5}$ ? Ou, não poderia se aceitar a matemática como a materialização de uma racionalidade $^{6}$ ? Ou ainda, mais prontamente aceito, a matemática como uma Ideia ${ }^{7}$ ?

Nessas inquietações, uma compreensão: a matemática surge no mundo, junto com o próprio mundo; portanto, trata-se de descobrir a matemática que compõe o mundo, a natureza ou que aparece como cópia de uma Ideia... Aquilo que se poderia chamar de invenção de matemática, seria, mais claramente, invenção na matemática. Invenção de relações, propriedades, conceitos que compõem o escopo daquilo que se denomina matemática. Ela mesma, a matemática, tendo seus elementos constituídos ou na chamada natureza, ou no Mundo das Ideias.

\footnotetext{
${ }^{4}$ Nesta visão, a matemática seria aquela que rege os fenômenos da natureza, na materialidade do mundo. A Matemática explica a ordenação do Universo, tirando-o do caos em que se encontra originariamente. Produz ordem no mundo e faz com que a natureza se rende aos seus princípios. Uma visão próxima a esta, consagrada na filosofia da matemática é a pitagórica, segundo a qual tudo é número. Os números regem o universo e organizam o caos.

${ }^{5}$ Visão da matemática como linguagem que expressa as leis da natureza pode estar associada ao pensamento de Galileu Galilei e é bastante difundida: a matemática é o alfabeto segundo o qual Deus criou o universo. Mais precisamente, nas palavras de Galileu: "A filosofia encontra-se escrita neste grande livro que continuamente se abre perante nossos olhos (isto é, o universo), que não se pode compreender antes de entender a língua e conhecer os caracteres com os quais está escrito. Ele está escrito em língua matemática, os caracteres são triângulos, circunferências e outras figuras geométricas, sem cujos meios é impossível entender humanamente as palavras; sem eles nós vagamos perdidos dentro de um escuro labirinto" (GALILEU, 1999/1623, p. 46).

6 "Na modernidade, uma certa racionalidade vai se tornando hegemônica: a matemática é o modelo de tal racionalidade. Assim, matemática e racionalidade se identificam" (CLARETO, 2003, p. 34). A matemática se confunde com esta racionalidade; mais do que isso: ela é sua expressão mais fiel.

${ }^{7} \mathrm{Na}$ concepção platônica Ideia teria um sentido "técnico de realidade em si, por si, separada das coisas que dela participam" (PLATÃO, 2001, p. 113). Ela seria o próprio princípio da identidade e a possibilidade da identificação. O mundo das Ideias abriga os entes matemáticos, objetos ideais, que constituem a matemática.
} 
Naquela sala de aula, aquele aluno lança uma questão, inventa um problema ${ }^{8}$ e impõe uma perspectiva: a matemática como uma invenção. Uma pergunta que se desdobra, então, de ordem gramatical: este verbo "inventar" pode ser conjugado no presente? Quer dizer, a pergunta poderia ser: quem inventa matemática? Ou ainda, poderia ser afirmado que há invenção com matemática? Há?

Invenção? Que invenção?

Invenção, invenire, composição com restos: com que restos compõe uma matemática? Que forças, que quereres compõem com restos de uma experiência? Como esta composição se nomeia matemática? Que matemática?

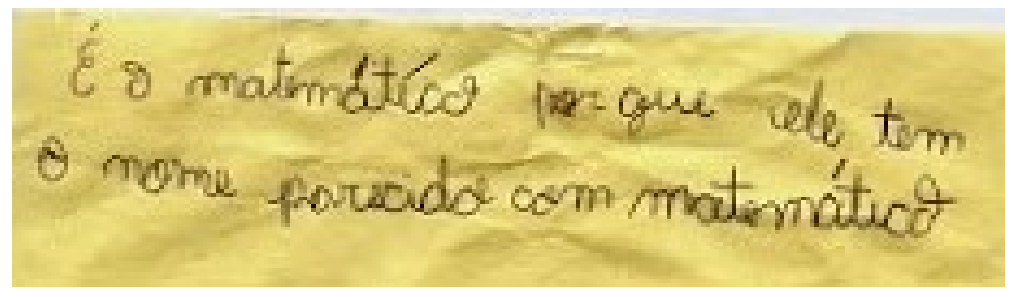

Uma matemática como pensamento inventivo? Há?

O pensamento inventivo - e aqui sigo Gilles Deleuze - não nasce de uma reprodução, de uma representação, do lado de fora do pensamento, mas de um encontro com o lado de fora como um "outro" do pensamento, como aquilo que é estranho ao pensamento (TADEU, 2002, p. 7).

Há invenção de matemática? Há invenção com matemática? Há pensamento inventivo com e em matemática? Há?

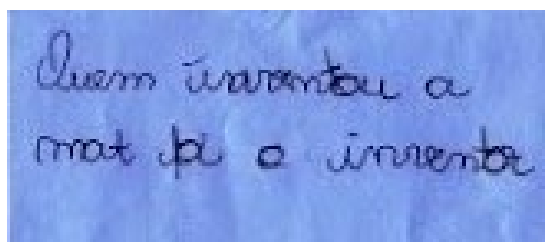

\section{Quem inventou a Matemática?}

Que matemática? Uma invenção?

O que é Matemática? Perseguindo essencialidades...

É a ciência do raciocínio lógico e abstrato que estuda quantidades, medidas, espaços, estruturas e variações. Ela procura por padrões, formula conjecturas e estabelece novos resultados, sempre por meio de deduções rigorosas a partir de axiomas e definições. Esse modo de proceder faz dela uma ciência rigorosa e precisa. Envolve uma permanente procura da verdade. Essa procura, numa visão moderna, é pelas estruturas abstratas definidas axiomaticamente.

\footnotetext{
8 “O problema e a questão não são determinações subjetivas, privativas, marcando um momento de insuficiência no conhecimento. A estrutura problemática faz parte dos objetos e permite apreendê-los como signos, assim como a instância questionante ou problematizante faz parte do conhecimento e permite apreender-lhe a positividade, a especificidade no ato de aprender" (DELEUZE, 2006, p. 103). O problema engendrando pensar no pensamento.
} 
Mas, O que é Matemática? “[...] Qualquer coisa ${ }^{9}$, desde que seu assunto mostrasse o padrão: hipótese-dedução-conclusão" (DAVIS; HERSH, 1985, p. 32).

Insistindo: $O$ que é Matemática? "A matemática, como uma expressão da mente humana, reflete a vontade ativa, a razão contemplativa e o desejo de perfeição estética. Seus elementos básicos são: lógica e intuição, análise e construção, generalidade e particularidade $^{10 "}$ (COURANT; ROBBINS, 1955, p. 3).

Insistindo mais um pouco: $O$ que é Matemática? "É aquilo que os matemáticos fazem quando dizem que estão fazendo matemática" $"$.

$O$ que é Matemática?... A pergunta o que é? remete a uma busca por uma essencialidade, pela substância daquilo que é. $\mathrm{O} o$ que é remete à definição da coisa, à sua essência, à sua delimitação. O o que é? aponta para a busca pela substância, pela definição da existência de algo.

Atritando o o que é matemática? com o quem inventou a matemática?: faíscas. Se se busca pela substância ou pela definição da existência de algo, ao se perguntar $o$ que é, parece haver uma territorialidade bem definida: algo é e se busca pela definição daquela existência. Quando se pergunta por quem inventou algo, parece haver uma certa ruptura nesta territorialidade: algo não está ali, existindo desde sempre, mas algo surge, como inventado, naquele território: quem inventou?... Atrito!

Atritando: quem inventou com o que se inventou: que matemática? que matemática foi inventada? Outras faíscas! Que matemática?

Que matemática? Aquela praticada na sala de aula.

\section{Quem inventa matemática na escola?}

A recolocação da questão - quem inventa matemática? Quem inventa matemática praticada na escola? Que forças, que quereres compõem com restos em uma matemática praticada na escola? - inventa problema.

Uma teia captura enfrentamentos de um problema: quem inventou a Matemática?. Uma outra teia - o currículo - captura enfrentamentos da questão recolocada: quem inventa matemática na escola? Uma teia: tensões heterogêneas em múltiplas conexões, múltiplas

\footnotetext{
${ }^{9}$ David e Hersh estão se referindo aqui à afirmação do matemático e filósofo pragmatista Charles Sanders Peirce (1839-1914) de que "matemática é a ciência que tira as conclusões necessárias".

10 "La matemática, como una expresión de la mente humana, refleja la voluntad activa, la razón contemplativa y el deseo de perfección estética. Sus elementos básicos son: lógica e intuición, análisis y construcción, generalidad y particularidad" (COURANT; ROBBINS, 1955, p. 3).

${ }^{11}$ Anotações pessoais de aulas do prof. Dr. Roberto Ribeiro Baldino, em 1991.
} 
entradas... Um currículo? Um currículo inventado pela colocação de uma pergunta que se coloca como problema: problema engendrando pensar, problema inventando currículo.

\begin{abstract}
Em geral, um currículo é definido por um conjunto de saberes. [..] E se o currículo, em vez disso, fosse concebido como um encontro, uma composição? Isso não mudaria tudo? Poderíamos começar por imaginar que corpos, os mais heterogêneos, os mais disparatados, os mais improváveis ("sorvete flambado com suspiro"), se encontram e se combinam no currículo, para compor um agenciamento-currículo particular. Imaginar o currículo desse modo aparentemente contraria a experiência ordinária. Mas é exatamente o contrário: é a concepção canônica que contraria a experiência ordinária que temos do currículo (TADEU, 2002, p. 55, grifo nosso).
\end{abstract}

Currículo? Um agenciamento no qual entram múltiplos elementos, em múltiplas entradas: saberes com disciplinas com indisciplinas com cheiros com cores com sabores com regras com amores com paixões com frustrações com aulas com explicações com recreios com bolas com chutes com gritinhos com berros com brincadeiras com sons com medos com ritmos com encantos com implicações com desencantos com música com alunos com professores com alunas com adolescentes com professoras com desentendimentos com mães com pais com árvores com pedras com complicações com desenhos com palavras com escritas com... com... com... Não em uma simples justaposição, mas em composição, em agenciamentos.

\footnotetext{
Denominaremos agenciamento todo conjunto de singularidades e de traços extraídos do fluxo - selecionados, organizados, estratificados - de maneira a convergir (consistência) artificialmente e naturalmente: um agenciamento, nesse sentido, é uma verdadeira invenção (DELEUZE; GUATTARI, 2012, p. 94).
}

Um currículo enquanto agenciamento faz convergir, artificial e naturalmente, singularidades e traços extraídos do fluxo cotidiano da escola e da matéria fluida da vida. Agenciamentos.

A pergunta: Professor, quem inventou a matemática? dispara agenciamentos múltiplos: um currículo: foi Arquimedes com os dinossauros com deus, com os homens da caverna com os alienígenas com a história da matemática com os gregos com os romanos com os portugueses com os índios com os professores com a escola com o cientista com os matemáticos com Galileu Galilei com o inventor com os seres humanos com jesus com... com... com...

Agenciamentos: encontro de corpos, entre corpos, com corpos. Em multiplicidade. O quem? já é um universo, agenciamento de forças com quereres. A invenção, já é agenciamento de corpos com quereres com forças com... Multiplicidade... A matemática, agenciamento de corpos com quereres com forças com números com matemáticos com formas com quantidades com cientistas com homens das cavernas com simetrias com romanos com gregos com equivalências com portugueses com índios com equações com espaços com tempos com forças com quereres com... com... com... 
Ainda, quem inventa matemática na escola? Um currículo? Um agenciamento de corpos com materialidades com saberes historicamente constituídos com saberes instituídos em uma sociedade com quereres com professores com alunos com livros didáticos com listagens oficiais de conteúdos com habitualidades com saberes que atravessam indisciplinarmente as disciplinas escolares com modos de proceder com didatismos com pedagogismos com crenças com acordos com desacordos com compreensões com dissabores com explicações com incompreensões com implicações com exercícios com "siga o modelo" com demonstrações com projetos com perguntas com respostas com não-respostas com enfrentamentos com ausências com passividades com... com... com...
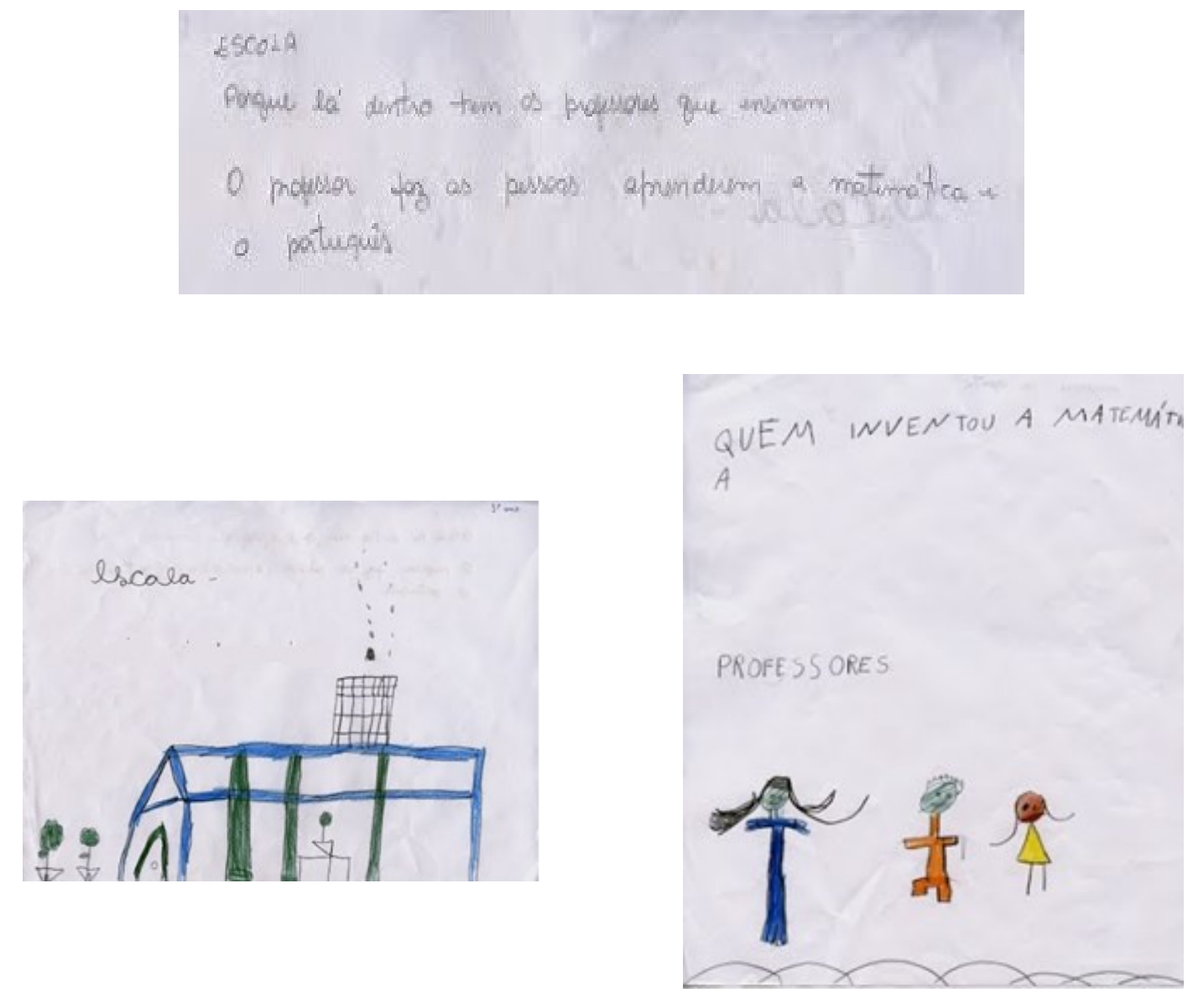

Como atritar matemática, escola e invenção? Num agenciamento curricular? 


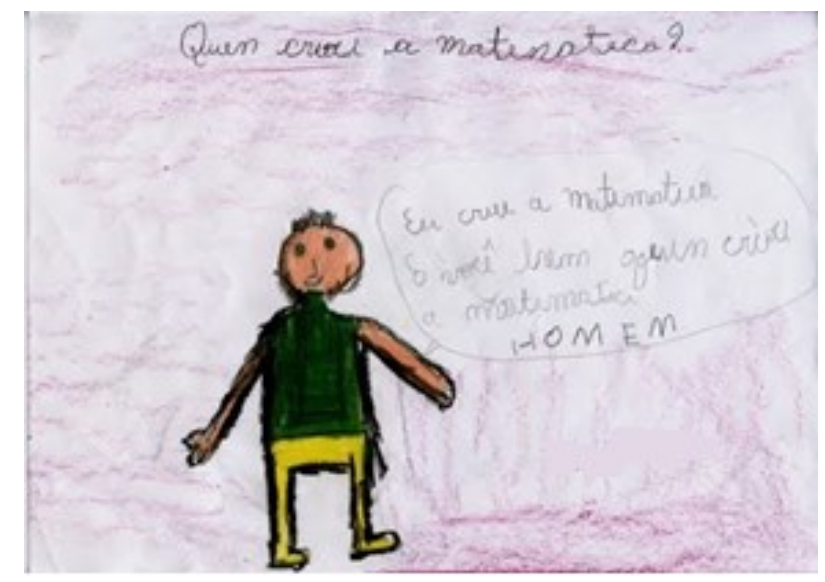

\section{Professor, quem inventou a matemática?}

\section{Referências}

CLARETO, Sônia M. Terceiras Margens: um estudo etnomatemático de espacialidades em Laranjal do Jari (Amapá). Tese (Doutorado em Educação Matemática) - Instituto de Geociências e Ciências Exatas, Universidade Estadual Paulista Júlio de Mesquita UNESP, Campus de Rio Claro, 2003.

COURANT, Richard; ROBBINS, Herbert. ¿Que es la matemática? Una exposición elemental de sus ideas y sus métodos. Traducción Luis Bravo Gala. Madrid: Aguilar Ediciones, 1955. Disponível em: http://personal.cimat.mx:8181/ gil/docencia/2010/elementales/cap1.pdf. Acesso em: 10 jan. 2013.

DAVIS, Philip; HERSH, Reuben. A Experiência Matemática. Tradução de João Bosco Pitombeira. Rio de Janeiro: Francisco Alves, 1985.

DELEUZE, Gilles. Diferença e repetição. Trad. Luiz B. L. Orlandi, Roberto Machado. Rio de Janeiro: Graal, 2a ed., 2006.

DELEUZE, Gilles. O mistério de Ariadne segundo Nietzsche. In: DELEUZE, Gilles. Crítica e Clínica. Tradução de Peter Pál Pelbar. São Paulo: Editora 34, 1997.

DELEUZE, Gilles; GUATTARI, Félix. Mil Platôs: Capitalismo e Esquizofrenia. v. 5. Tradução de Peter Pál Pelbar e Janice Caiafa. São Paulo: Editora 34, 2012.

GALILEU, G. O Ensaiador. Trad. Helda Barraco. SP: Nova Cultura, 1999/1623. (Os Pensadores).

PLATÃO. Mênom. Rio de Janeiro: Loyola, 2001.

TADEU, Tomaz. A arte do encontro e da composição: Spinoza + Currículo + Deleuze. Educação e Realidade. Porto Alegre, v. 27, n. 2, p. 47-57, jul./dez. 2002.

TADEU, Tomaz. Mapeando a [complexa] produção teórica educacional - Entrevista com Tomaz Tadeu da Silva. Entrevista concedida a Luís Armando Gandin, Universidade Federal do Rio Grande do Sul - Brasil, João M. Paraskeva, Universidade do Minho - Portugal, e Álvaro Moreira Hypolito, Universidade Federal de Pelotas - Brasil. Currículo sem Fronteiras, v.2, n.1, p. 5-14, Jan./Jun. 2002. 